\title{
Prevalence and Determinants of Delayed Newborn Bathing among Postnatal Mothers in a Rural Community of Northern Ghana
}

\author{
John Ndebugri Alem, \\ Faculty of Health and Allied Sciences, \\ Catholic University College of Ghana, Sunyani, Ghana \\ Prof Ernestina S. Donkor, \\ School of Nursing and Midwifery, \\ University of Health and Allied Sciences, Ho, Volta Region Ghana \\ Dr. Florence Naab, \\ Department of Maternal and Child Health, \\ School of Nursing and Midwifery, University of Ghana, Accra, Ghana
}

Doi:10.19044/esj.2020.v16n18p155 URL:http://dx.doi.org/10.19044/esj.2020.v16n18p155

Abstract

Globally, an estimated 2.7 million deaths, approximately $45 \%$ of under-five deaths occurred in the neonatal period in 2015. This trend led to the inability of many countries to achieve the Millennium Development Goal four (MDG 4) by 2015; hence the introduction of the Sustainable Development Goals (SDGs). Many studies have concluded that poor newborn care including early newborn bathing accounts for high levels of newborn deaths in lowmiddle income countries. This study therefore investigated the prevalence and determinants of delayed newborn bathing among postnatal mothers in Bawku Municipality in the Upper East Region of Ghana. As a community based study, a cross sectional study design was employed using multistage sampling technique to select 407 respondents. The Statistical Package for Social Sciences (SPSS) version 22 now known as Predictive Analytics Software (PASW) was used for data analysis. Generally, knowledge on delayed bathing was low as more than half of the respondents, 55\% $(n=224)$ did not know that newborns are not supposed to be bathed until after 24hours of delivery. With regard to delayed bathing practice, only $22.6 \%(\mathrm{n}=92)$ of mothers bathed their newborn babies after 24 hours of delivery whereas $74.4 \%$ ( $\mathrm{n}=$ 303 ) bathed their newborn babies before 24 hours of delivery. In the final analysis, delayed newborn bathing was predicted by level of education, place of delivery, ethnicity and socioeconomic class. These findings suggest that a substantial number of newborns still receive harmful newborn care practice and these practices are determined by several factors as stated above. Rigorous 
efforts should therefore be made by the Ministry of Health through the Ghana Health Service and other stakeholders to improve the uptake of recommended newborn care practices at the community

Keywords: Bathing, Care, Delayed, Determinants and Newborn

\section{Introduction}

Child mortality worldwide is decreasing and many countries made significant strides towards achieving Millennium Development Goal four (MDG4) which sought to reduce child mortality by two thirds from 1990 to 2015. However, the worrying trend is that, though there is significant improvement in child mortality, a greater percentage of these deaths occur during the neonatal period. Between 1990 and 2011 the proportion of child deaths in the neonatal period increased to $41 \%$ globally (Bhutta, Cabral, Chan, \& Keenan, 2012). Again, an estimated 2.4 million newborns die globally each year, with the majority occurring during delivery (Ameh \& van den Broek, 2015). Due to less attention, newborn deaths now account for about $44 \%$ of all deaths among children under the age of five years globally, and a total 2.8 million deaths annually (Kinney et al., 2015).

With the end of the MDG era where most countries had failed to achieve some of the goals, member nations agreed on a new set of goals - the Sustainable Development Goals (SDGs). The proposed SDG target for child mortality is to end preventable deaths of newborns and children under-five years of age by 2030. As such, all countries are aiming to reduce neonatal mortality to at least 12 deaths per 1,000 live births by 2030 . However, if the current trends in neonatal mortality continue, meeting these goals will be a very difficult task for most nations. Evidence available points to the fact that a significant number of neonatal deaths are preventable by inexpensive and simple practices such as the Essential Newborn Care package and interventions along the continuum of maternal and newborn health (Bang, Lee, Chae, Debeb, \& Kang, 2015; Bhutta et al., 2014).

As a response to the persistent increase in neonatal mortality, the WHO developed a minimum newborn care package (Essential Newborn Care) to help improve the health of newborns (World Health Organization, 2009). Under this package, the WHO recommends that a newborn baby is not supposed to be bathed until after 24hours of delivery; hence, bathing a newborn within the first 24 hours of delivery is a bad practice. Since delayed newborn bathing was a significant contributor to a reduction in neonatal mortality in Bangladesh (Akter, Dawson, \& Sibbritt, 2015), there is the need to encourage delayed newborn bathing in lower-middle income settings. That notwithstanding, Lawn et al. (2013) argued that there is insufficient evidence regarding the exact number of hours to delay, especially if it can be a warm 
bath and done in a warm room. Underpinning this argument, it is evident that a gap exist between policy dissemination and implementation; hence the need to revise the modalities of educating the populace on modern and beneficial practices.

Even though there is enough evidence to support the benefits of delayed newborn bathing, it is the most poorly practiced component of the essential newborn care package, especially in sub-Saharan Africa. In a study conducted by Callaghan-Koru et al. (2013), harmful practices that were reported include newborn bathing within 24 hours of delivery (74.7\%). Moreover, in a cross sectional study by Gul, Khalil, Yousafzai, and Shoukat (2014), 86\% of respondents reported that the first bath of their newborns was within $24 \mathrm{hrs}$ of delivery in Pakistan. This situation is not different from the practice in Africa as delayed bathing was found among only $32.6 \%$ of Ethiopian women (Berhe, Medhaniye, Kahsay, Birhane, \& Abay, 2017). In spite of the differences in sample sizes, the similarities in methodological approach could be accountable for the consistent findings in these studies. On the contrary however, a very recent study by Semanew, Etaye, Tizazu, Abebaw, and Gebremedhin (2019) found that 75.8\% of newborns were bathed after 24hours of delivery in a referral Hospital in Northeast Ethiopia.

Although the factors determining the practice of delayed newborn bathing have been widely studied and reported, other factors identified have not been consistent with earlier studies (Akter, Dawson, \& Sibbritt, 2016). For instance, mothers' education, antenatal care and the presence of SBAs were found to have a positive influence on the practice of good thermal care in Nepal (Khanal, Gavidia, Adhikari, Mishra, \& Karkee, 2014). In another study, antenatal care (ANC) visit, advice about essential newborn care practice, living in urban area and knowledge about newborn danger signs were independent predictors of ENC practices (Chichiabellu, Mekonnen, Astawesegn, Demissie, \& Anjulo, 2018). Conversely, an earlier study in India found that ANC visits and the presence of skilled birth attendants (SBAs) were not significantly associated with good thermal care (Baqui et al., 2007).

As might be expected, mothers who receive higher level of education should be more likely to practice good thermal care than illiterate mothers or mothers with lower levels of education. In a community based cross sectional study, Tegene, Andargie, Nega, and Yimam (2015) reported level of education and knowledge of newborn bathing time as significant predictors of good newborn care practices. Mothers with high education and above were more likely to practice good thermal care; likewise mothers who had knowledge on delayed bathing. This is consistent with the finding of Kokebie, Aychiluhm, and Alamneh (2015) where educational status was a significant predictor of essential newborn care practices which includes good thermal care. These findings are not surprising because women who are highly educated are more 
likely to have a better understanding of the benefits of delayed newborn bathing. Corroborating this assertion, Shoaib, Munir, Masood, Ali, and Sher (2012), reported that women with formal education were more likely to ignore cultural practices and use modern services that promote good health

Currently, the practice of delayed newborn bathing among postnatal women is low in Ghana (Saaka \& Iddrisu, 2014) probably due to lack of resources, low commitment and inadequate planning and management of the newborn health workforce. According to Ameh and van den Broek (2015) early newborn bathing is associated with poor implementation of evidence-based interventions, cultural and traditional beliefs, illiteracy, and low socioeconomic status.

Moreover, the essential newborn care package which includes delayed newborn bathing was launched in the Upper East Region in 2012 by the Ghana Health Service (GHS) in partnership with UNICEF, with Bawku Municipality being one of the implementation districts. The Bawku Municipality is predominantly rural with majority of women being illiterates and home deliveries still occur. Despite the implementation of the essential newborn care package, the Bawku Municipality recorded 18 neonatal deaths in 2014 which is an increase from the 2013 figure of 16 (Bawku Municipal Health Directorate, 2014). Again, there is no literature about the practice of delayed newborn bathing in the study area and little is documented on the factors influencing the practice. This study therefore sought to assess the prevalence and determinants of delayed newborn bathing among post natal women in the Bawku Municipality.

\section{Methods}

\section{Study Design and Setting}

The study employed a quantitative approach; hence a cross sectional survey design was used to collect data from postnatal mothers about delayed newborn bathing. A cross sectional design is a non-experimental study design that allows the researcher to examine relationships between study variables: independent variables or exposure and the dependent or outcome variables within the population under study without manipulating any of the variables (Salkind, 2010). The study was conducted in Bawku Municipality in the Upper East Region. The Bawku Municipality with its administrative capital at Bawku is one of the 13 Municipal and District Assemblies in the Upper East Region of Ghana. According to the Ghana Statistical Service (2015), the Municipality has a population of 98,538 persons, with the males being 47,254 (48\%) and females 51,284 (52\%). The urban population is $63.6 \%$ whiles the rural population constitutes $36.4 \%$. The major ethnic groups in the municipality are Kussasis, Mamprusis, Bissangas and Moshies. Health care in the municipality is provided through hospitals, health centres and private clinics. There are four 
sub-districts in the municipality with the following health facilities: two Hospitals, seven Health Centres, four public clinics, five private facilities, nine community based health planning and services (CHPS) centres, and one Nurses Training School. The Doctor - Patient Ratio is 1: 8315 and Nurse Patient Ratio is 1: 551 in the municipality.

\section{Study Population}

The study population comprised all postnatal women in the Bawku Municipality in the Upper East Region. However, postnatal women with a live baby less than 12 months but did not deliver within the confines of the Bawku Municipality were excluded from the study. This was to avoid recall bias since the mothers with more than 12 months old babies may forget the exact practice that was adopted for their newborns.

\section{Sample Size}

The sample size for the study was calculated using Yamane (1967) formula for sample size determination. According to Yamane (1967), the sample size can be calculated if the population size of the target group is known. With a total number of deliveries of 5060 in in the Bawku Municipality in 2016 and an alpha level of 0.05, the sample size was calculated to be 370 . However, allowing for a non-response rate of $10 \%$, the final sample size for the study was 407 .

\section{Sampling Procedure}

A multistage sampling technique was employed to select respondents for this study in three stages. In the first stage, three (3) sub districts within the municipality were randomly selected for the study. In the second stage, each sub district was divided into clusters and in each cluster; a complete list of all households was compiled. In the third stage, a systematic random sampling technique was then used in selecting the respondents for the study. All the households in each cluster were serially numbered and the sampling interval computed. The first household was selected using simple random sampling and subsequent selection of households to visit was made by adding the sampling interval to the selected number. For households that were selected but did not have a target respondent, the next household was considered. This process continued until the required number of respondents was obtained in each cluster.

\section{Measurements}

A standard questionnaire developed by the Saving Newborn Lives Program was adapted and modified to meet the study objectives and answer the research questions appropriately. As part of the modification process of 
the questionnaire, some questions that were not applicable to the study setting were excluded from the current study. Data was collected on predisposing characteristic (sociodemographic factors: age, marital status, level of education, ethnicity, religious affiliation and parity), use of maternal services (antenatal care attendance and place of delivery) and enabling resources (knowledge on good thermal care, SEC and education/counselling on delayed newborn bathing). The socioeconomic class of respondents was measured using four variables: education status, employment status, type of employment and monthly income, with a total maximum score of 17 . A score or $1-6$ represents low SEC, 7 - 12 for middle SEC and 13 - 17 for high SEC. Finally, the outcome/dependent variable (practice of thermal care) was measured as a binary variable in two levels; early (before 24 hours of delivery) or delayed (after 24 hours of delivery) newborn bathing.

\section{Data Analysis}

The Statistical Package for Social Sciences (SPSS), now known as Predictive Analytics Software (PASW) version 22 was used to analyse the data. Both descriptive and inferential statistical analyses were carried out to meet the study objectives. Descriptive results took the form of frequencies, percentage distribution and presented in tables and pie charts. Furthermore, the multiple binary logistic regression analysis was used to determine the predictors of delayed newborn bathing in two models. This is because the dependent variable of the study was binary in nature (measured in two levels); which is an assumption of binary logistic regression modelling (Harrell, 2015). Since binary logistic regression also assumes that $\mathrm{P}(\mathrm{Y}=1)$ is the probability of the event occurring (Allison, 2012), the dependent variables was coded accordingly. Underpinning this assumption, delayed newborn bathing was coded into 0 and 1 , where 1 represents the preferred practice.

\section{Ethical Approval}

Ethical considerations are very important aspects of the research process. The ethical principles underlying research are general and concern issues such as privacy, anonymity, confidentiality, honesty, and respect for fundamental human rights (Munn-Giddings \& Winter, 2013). In conducting a research, the principles of confidentiality and the provision of appropriate information about the research must be safeguarded (Marianna, 2011). Therefore, ensuring that the research is approved by an appropriate ethical review board is a prime duty of the researcher. Based on this statement, ethical approval was sought and obtained from the Institutional Review Board of the Noguchi Memorial Institute for Medical Research (see appendix A) prior to data collection. Postnatal women who agreed to participate were also required to sign informed consent forms after the details and purpose of the study were 
explained to their understanding. For participants who were below 18 years of age, the parental consent form was signed by a guardian or a parent and the child assent form endorsed by the participant. The principle of anonymity and confidentiality were also adhered to; hence, the identity of participants was not a requirement on the questionnaire and the information provided was strictly confidential.

\section{Result}

\section{Socio demographic Characteristics of Respondents}

From the sample, majority of the respondents, $54.1 \%(n=220)$ were between 21-30 years and only 2.7\% $(\mathrm{n}=11)$ were above 40 years. Again, 94 respondents representing $23.1 \%$ were below 20 years whereas 82 respondents representing $20.1 \%$ were within the ages of $31-40$ years. The average age of the respondents was $26(\mathrm{SD}=6.411)$ with a minimum and maximum ages of 16 and 43 years respectively. With respect to education, a greater proportion of the respondents, $69.3 \%(n=282)$ received formal education at different levels whereas $30.7 \%(n=125)$ never had formal education. Table 1 presents details of socio demographic characteristics of respondents in the study

Table 1: Socio-demographic characteristics of respondents

\begin{tabular}{|c|c|c|c|}
\hline Variable & & Frequency & Percentage $(\%)$ \\
\hline \multirow[t]{5}{*}{ Age groups } & 20 and below & 94 & 23.1 \\
\hline & $21-30$ & 220 & 54.1 \\
\hline & $31-40$ & 82 & 20.1 \\
\hline & 40 and above & 11 & 2.7 \\
\hline & Total & 407 & 100 \\
\hline \multirow[t]{6}{*}{ Level of education } & $\begin{array}{ll}\text { No } & \text { formal } \\
\text { education } & \end{array}$ & 125 & 30.7 \\
\hline & Primary education & 93 & 22.9 \\
\hline & J. H. S & 94 & 23.1 \\
\hline & S. H. S & 66 & 16.2 \\
\hline & Tertiary & 29 & 7.1 \\
\hline & Total & 407 & 100 \\
\hline \multirow[t]{6}{*}{ Ethnicity } & Kusaasi & 112 & 27.5 \\
\hline & Busanga & 79 & 19.4 \\
\hline & Mooshie & 77 & 18.9 \\
\hline & Mamprusi & 73 & 17.9 \\
\hline & Others & 66 & 16.2 \\
\hline & Total & 407 & 100 \\
\hline \multirow[t]{4}{*}{ Religious affiliation } & Islam & 244 & 60 \\
\hline & Christianity & 155 & 38 \\
\hline & ATR & 8 & 2 \\
\hline & Total & 407 & 100 \\
\hline
\end{tabular}




\begin{tabular}{llcc}
\hline Marital status & Single & 37 & 9.1 \\
& Married & 387 & 87.7 \\
& Divorced & 5 & 1.2 \\
Widowed & 8 & 2 \\
& Total & 407 & 100 \\
Parity & & \\
& Primipara & 124 & 30.5 \\
& Multipara & 223 & 54.8 \\
& Grandmultipara & 60 & 14.7 \\
& Total & 407 & 100 \\
\hline
\end{tabular}

Source: Field Data, 201

\section{Use of maternal health services}

In this study, use of maternal services consists of ANC attendance and delivery care. From the findings, ANC attendance was universal, with all 407 respondents indicating to have attended ANC before delivery. However, not all the respondents attended the minimum number of four ANC attendances before delivery as recommended by the WHO. With regards to the number of attendance, majority of the respondents, $92.6 \%(\mathrm{n}=377)$ had four or more (adequate) ANC attendance before delivery; whilst the remaining 7.4\% ( $\mathrm{n}=$ 30) had less than four (inadequate) ANC visits before delivery. The average number of ANC attendance was $3.473(\mathrm{SD}=1.01)$ with a minimum and maximum number of attendance of 1 and 6 respectively.

In terms of delivery care, majority of the respondents received delivery services from a Skilled Birth Attendant (SBA) during delivery as $88.5 \%(\mathrm{n}=$ 260) women reported that they delivered at a health facility. Despite a universal ANC attendance, $11.5 \%(\mathrm{n}=47)$ women still delivered at home without an SBA. The results are displayed in Table 2 below.

Table 2: Utilisation of SBA

\begin{tabular}{llcc}
\hline Variable & & $\begin{array}{c}\text { Frequency } \\
(\mathbf{n})\end{array}$ & $\begin{array}{c}\text { Percentage } \\
(\mathbf{\%})\end{array}$ \\
\hline Antenatal care attendance & $\begin{array}{l}\text { Adequate } \\
\text { Inadequate }\end{array}$ & 377 & 92.6 \\
& $\begin{array}{c}\text { Total } \\
\text { Average number of attendance (SD): 3.47 }( \pm 1.01)\end{array}$ & $\begin{array}{c}407 \\
\text { Minimum: } 1\end{array}$ & 100 \\
$\begin{array}{l}\text { Maximum: } 6 \\
\text { Place of delivery }\end{array}$ & $\begin{array}{l}\text { Facility } \\
\text { delivery }\end{array}$ & 260 & 88.5 \\
& $\begin{array}{l}\text { Home } \\
\text { delivery } \\
\text { Total }\end{array}$ & 47 & 11.5 \\
\hline
\end{tabular}

Source: Field Data, 2017

\section{Enabling Resources of Respondents}

In this study, enabling resources of the respondents include knowledge on Essential Newborn Care practices, education or counselling on ENC 
practices and socioeconomic class (SEC). As shown in table 3 below, the findings revealed that knowledge on delayed bathing was low as more than half of the respondents, 55\% $(n=224)$ disagreed with delayed newborn bathing item. Only $29.3 \%(n=119)$ represents those who agreed to delayed newborn bathing whilst $15.7 \%(n=64)$ neither agreed no disagreed. In terms of socioeconomic status (SEC), the results showed that majority of them, $57.7 \%(n=235)$ were in the middle class whilst only $11.6 \%(n=47)$ were in the high SEC. Moreover, 125 respondents, representing $30.7 \%$ were in the low SEC. Moreover, $80.8 \%(n=329)$ of the respondents indicated that they were educated or counselled on delayed newborn bathing, whilst $19.2 \%(\mathrm{n}=78)$ respondents were not.

Table 3: Enabling Resources of Respondents

\begin{tabular}{llcc}
\hline Enabling Resource & & $\begin{array}{c}\text { Frequency } \\
(\mathbf{n})\end{array}$ & $\begin{array}{c}\text { Percentage } \\
(\mathbf{\%})\end{array}$ \\
\hline Socioeconomic Class & Low & 125 & 30.7 \\
& Middle & 235 & 57.7 \\
& High & 47 & 11.6 \\
& Total & 407 & 100.0 \\
Knowledge on delayed newborn & Disagree & 224 & 55.0 \\
bathing. & Agree nor Disagree & 64 & 15.7 \\
& Agree & 119 & 29.3 \\
& Total & 407 & 100.0 \\
Education/counselling on delayed & Yes & 328 & 80.8 \\
newborn bathing & No & 78 & 19.2 \\
& Total & 407 & 100.0 \\
\hline
\end{tabular}

Source: Field Data, 2017

\section{Practice of Delayed Newborn Bathing}

With regards to delayed bathing practice, only $22.6 \%(n=92)$ of mothers bathed their newborn babies after 24 hours of delivery. The majority of them, $74.4 \%(n=303)$ bathed their newborn babies before 24 hours of delivery and $3 \%(\mathrm{n}=12)$ of mothers could not remember the time their newborn babies were bathed. The results are presented in Fig 1 below.

Fig 1: Pie chart showing the prevalence of delayed newborn bathing.

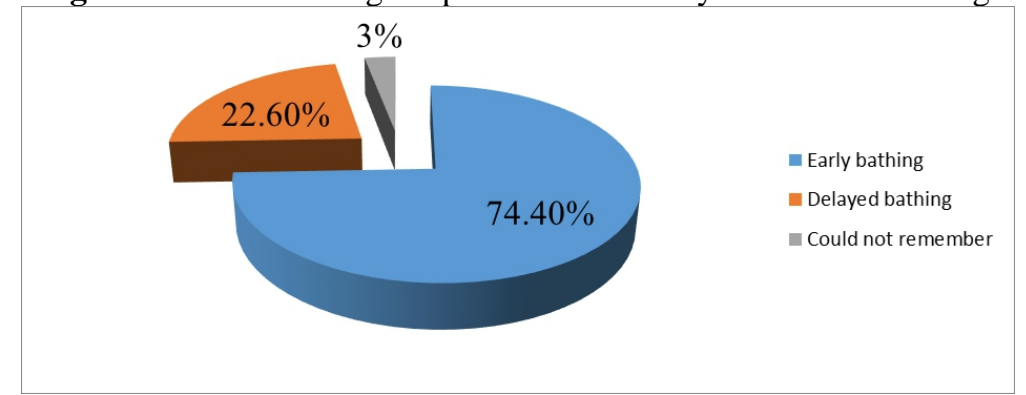

Source: Field Data, 2017 


\section{Predictors of Delayed Newborn Bathing}

To determine the predictors of delayed newborn bathing, the simple binary logistic regression analysis was used to examine the relationships between each of the independent variables and the practice of good thermal care. The Odds Ratios (OR) and the 95\% confidence intervals of each independent variable were recorded. The results showed that SEC, ethnicity, level of education, parity, place of delivery and knowledge on good delayed newborn bathing had a statistically significant relationship with the practice of same. In terms of parity, an increase by one, leads to an increase in the odds of practicing delayed newborn bathing by 1.388 . This implies that, as parity increases, there is 1.388 times likelihood of practicing delayed newborn bathing. Similarly, the odds of practicing delayed newborn bathing increase by 1.166 as knowledge increases. However, age, religious affiliation and education/counselling on good thermal care had no significant relationship with the practice of delayed newborn bathing; hence, were excluded from the multiple regression analysis. The results are presented in Table 4 below.

Table 4: Simple logistic regression analysis results, showing the relationship between predisposing characteristics, enabling factors and delayed newborn bathing

\begin{tabular}{|c|c|c|c|c|}
\hline Variables & Sig. & OR & $\begin{array}{l}\text { 95\% C.I } \\
\text { Lower }\end{array}$ & Upper \\
\hline SEC & .000 & & & \\
\hline Low class (Reference category) & .000 & .203 & .087 & .473 \\
\hline Middle class & .189 & .633 & .320 & 1.253 \\
\hline Ethnic background & .005 & & & \\
\hline Kusaasi (Reference category) & .001 & .313 & .154 & .637 \\
\hline Busanga & .012 & .381 & .179 & .809 \\
\hline Mooshie & .007 & .341 & .156 & .744 \\
\hline Mamprusi & .359 & .715 & .349 & 1.465 \\
\hline Level of education & .000 & & & \\
\hline $\begin{array}{l}\text { No formal education (Reference } \\
\text { category }\end{array}$ & .006 & .282 & .115 & .696 \\
\hline Primary & .058 & .414 & .116 & 1.029 \\
\hline Junior High School & .021 & .334 & .132 & .848 \\
\hline Senior High School & .795 & 1.128 & .456 & 2.791 \\
\hline Parity & .003 & 1.388 & 1.118 & 1.723 \\
\hline Place of delivery & .006 & .061 & .008 & .452 \\
\hline Knowledge on good thermal care & .035 & 1.166 & 1.011 & 1.346 \\
\hline
\end{tabular}

\section{Dependent variable: Delayed newborn bathing, criterion level: 0.05}

Subsequently, a multiple logistic regression analysis was used to determine if predisposing characteristics (model 1) and a combination of 
predisposing characteristics and enabling factors (model 2) significantly predict the practice of delayed newborn bathing. In the first model, predisposing characteristics (level of education, parity, ethnicity and place of delivery) accounted for $16.6 \%$ of the practice of delayed newborn bathing [ $\mathrm{R}^{2}$ $\left.=.166, \chi^{2}{ }_{(10)}=45.987, \mathrm{p}<.001\right]$. The individual predisposing characteristics that contributed significantly to the model were level of education, place of delivery, and ethnicity. Surprisingly, parity did not contribute significantly to the model.

In the second model, enabling resources (socioeconomic class and knowledge on good thermal care) were included to examine the combined effect of the variables on delayed newborn bathing. The results showed that predisposing characteristics together with enabling factors significantly predicted approximately $19 \%$ of the practice of delayed newborn bathing $\left[\mathrm{R}^{2}\right.$ $\left.=.187, \chi_{(13)}^{2}=52.358, \mathrm{p}<.001\right]$. Level of education, place of delivery and ethnicity retained their significance in the second model. In addition, socioeconomic status was found to have a significant relationship with good thermal care; whereas parity and knowledge on good thermal care were not. Therefore, the final predictors of delayed newborn bathing were level of education, place of delivery, ethnicity and socioeconomic class. Table 5 presents the details of the results.

Table 5: Multiple logistic regression analysis results showing the predictors of delayed newborn

\begin{tabular}{|c|c|c|c|c|c|c|}
\hline Model & Variables & B & Sig. & OR & $\begin{array}{l}\text { 95\% C.I } \\
\text { Lower }\end{array}$ & Upper \\
\hline \multirow{12}{*}{ Model 1} & Level of education & & .014 & & & \\
\hline & No formal education & -.713 & .193 & .490 & .168 & 1.433 \\
\hline & Primary education & -.946 & .072 & .388 & .139 & 1.088 \\
\hline & J.H.S & -.914 & .072 & .401 & .148 & 1.087 \\
\hline & S.H.S & .258 & .592 & 1.295 & .504 & 3.329 \\
\hline & Parity & .007 & .960 & 1.007 & .763 & 1.330 \\
\hline & Place of delivery & -2.559 & .013 & .077 & .010 & .588 \\
\hline & Ethnicity & & .036 & & & \\
\hline & Kusaasi & -.971 & .013 & .379 & .175 & .817 \\
\hline & Busanga & -.822 & .044 & .440 & .198 & .976 \\
\hline & Mooshie & -1.084 & .011 & .338 & .147 & .777 \\
\hline & Mamprusi & -.301 & .435 & .740 & .348 & 1.574 \\
\hline \multicolumn{7}{|c|}{ Model 1 summary: $\left[R^{2}=.166, \chi^{2}{ }_{(10)}=45.987, p<.001\right]$} \\
\hline
\end{tabular}




\begin{tabular}{lllllll}
\hline Model 2 & Level of education & & $\mathbf{. 0 3 2}$ & & & \\
& No formal education & -.009 & .988 & .991 & .281 & 3.488 \\
Primary education & -.638 & .259 & .528 & .174 & 1.600 \\
J.H.S & -.811 & .133 & .444 & .154 & 1.279 \\
S.H.S & .310 & .531 & 1.363 & .517 & 3.590 \\
Ethnicity & & $\mathbf{. 0 2 3}$ & & & \\
Kusaasi & -1.031 & $\mathbf{. 0 1 0}$ & .357 & .163 & .780 \\
Busanga & -.849 & $\mathbf{. 0 4 0}$ & .428 & .191 & .961 \\
Mooshie & -1.116 & $\mathbf{. 0 0 9}$ & .328 & .142 & .757 \\
Mamprusi & -.257 & .512 & .774 & .359 & 1.667 \\
Parity & .002 & .990 & 1.002 & .745 & 1.348 \\
Place of delivery & -2.399 & $\mathbf{. 0 2 1}$ & .091 & .012 & .700 \\
SEC & & $\mathbf{. 0 5 0}$ & & & \\
Low class & -1.212 & $\mathbf{. 0 3 3}$ & .298 & .097 & .909 \\
Middle class & -.220 & .587 & .802 & .362 & 1.778 \\
Knowledge on good thermal & -.010 & .915 & .990 & .825 & 1.188 \\
care practices & & & & & \\
\hline
\end{tabular}

Dependent variable: Delayed newborn bathing, Criterion level: 0.05

\section{Discussion}

The study sought to determine the prevalence and determinants of delayed newborn bathing among postnatal mothers in Bawku Municipality, Ghana. As recommended by the WHO, a newborn baby is not supposed to be bathed until after 24hours of delivery (World Health Organization, 2012); hence, bathing a newborn within the first 24hours of delivery is a bad practice. Home delivery, low birth weight, and early bathing of babies are risk factors of hypothermia in sub-Saharan Africa (Onalo, 2013). Although hypothermia is rarely a direct cause of neonatal death, it has been reported as an important indirect contributor to neonatal mortality globally (Lunze, Bloom, Jamison, \& Hamer, 2013; Seyum \& Ebrahim, 2015). It is also evident that delayed bathing contributes to a reduction in neonatal mortality in low and lower-middle income countries. In Bangladesh, delayed bathing significantly contributed to an improvement in newborn health, hence a reduction in neonatal mortality (Akter et al., 2015).

From the findings of this study, ANC attendance was universal, with all 407 respondents indicating to have had at least one ANC visit before delivery which is higher than the national rate $(91 \%)$. This can be attributed to the expansion of the healthcare delivery system through the introduction of the CHPS concept to increase access to and use of health services in remote communities. Similar to what has been reported in this study, 97\% of pregnant women had at least one ANC visit before delivery in the Upper East Region (Pell et al., 2013). Additionally, Afulani (2015) also found that $96 \%$ of Ghanaian women had at least one antenatal care visit while pregnant. On the contrary, as high as $29.7 \%$ of pregnant women never attended ANC in Kenya 
(King'oo, 2015), and over one third of pregnant women in Nigeria do not attend ANC service during pregnancy (Fagbamigbe \& Idemudia, 2015).

Despite the global and local attention and commitment made towards maternal health since the inception of the MDGs, there are still low levels of adequate ANC attendance in some countries. Though ANC attendance was universal in this study, not all the respondents had the minimum number of four ANC attendances before delivery. The proportion of women who had at least four visits before delivery $(92.6 \%)$ in the current study was consistent, but slightly higher than the national rate $(87 \%)$ and that of the 2015 figure of the Bawku Municipality (84.9\%). Given the rural nature of the study area, the factors that could influence adequate ANC visits may include poor access, cultural beliefs, financial constraints and level of education. Corroborating this assertion, Gitonga (2017) found that women with higher level of education were more likely to attend more antenatal care visits. That notwithstanding, the finding is encouraging and indicates good progress towards achieving the WHO recommendation.

Similar to the finding in the present study, Muhwava, Morojele, and London (2016) in a cross sectional study found that $84 \%$ of women had a minimum of four antenatal care visits before delivery. On the contrary, low levels of adequate number of ANC visits have been reported in other subSaharan African countries, with $56.2 \%$ in Nigeria (Fagbamigbe \& Idemudia, 2017) and $42.3 \%$ in Uganda (Ayiasi, Kasasa, Criel, Orach, \& Kolsteren, 2014). With a universal ANC attendance as reported in the study, one would expect a universal facility delivery with a skilled birth attendant; given that ANC attendance is a one of the determinants of choice of place of delivery. In a study on determinants of health facility utilization for childbirth in rural western Kenya, Kawakatsu et al. (2014) found ANC attendance as one of the significant determinants of facility delivery. In this study, majority of the respondents delivered in a health facility with a SBA $(88.5 \%)$; whereas $11.5 \%$ delivered at home without an SBA despite a universal ANC attendance. Similarly, Enuameh et al. (2016) found that $75.6 \%$ of respondents had facility deliveries whilst $24.4 \%$ delivered at home. Kabwijamu et al. (2016) also found that $78.8 \%$ and $21.2 \%$ of respondents had facility and home deliveries respectively in Western Uganda. Contradicting these findings, only $18.8 \%$ of births were attended by skilled attendants in Ethiopia (Alemayehu \& Mekonnen, 2015), 13\% in Nigeria (Adewemimo, Msuya, Olaniyan, \& Adegoke, 2014), and 39.8\% of women delivered at home in rural Ghana (Dickson, Adde, \& Amu, 2016).

Moreover, the current study found that more than half of the respondents $(80.8 \%)$ received education or counselling on good thermal care practices. This agrees with that of Renfrew et al. (2014) where a greater proportion of postnatal women indicated to have received education on safe 
newborn care practices. Similarly, more than $50 \%$ of mothers were counselled on safe newborn care in Ethiopia (Sibley et al., 2014). This trend of high maternal education or counselling on safe newborn care practices is attributable to the increasing attention given to newborn health, both globally and locally. According to Rama, Gopalakrishnan, and Udayshankar (2014), creating awareness about essential newborn care practices among mothers through education is a key step in achieving the goals of specific child health programmes. The relevance of this was shown by Sines, Syed, Wall, and Worley (2007) who demonstrated that health education information from a skilled health provider optimizes mother and newborn health, promote healthy behaviour and health household practice. However, educating and counselling mothers on essential newborn care is not a guarantee for the practice of good newborn care. That notwithstanding, there is the need for health workers to intensify the modalities for educating post natal women on safe newborn care practices.

With regards to delayed bathing practice, the current study found that only $22.6 \%$ of mothers bathed their newborn babies after 24 hours of delivery. A majority of them, $74.4 \%$ bathed their newborn babies before 24 hours of delivery whilst $3 \%$ of mothers could not remember the time their newborn babies were bathed. This is consistent with the findings of Gul et al. (2014) where $86 \%$ of respondents reported first bath within $24 \mathrm{hrs}$ of birth in Pakistan. Similarly, it was reported by Waiswa, Kallander, Peterson, Tomson, and Pariyo (2010) that more than half (58\%) of newborns had poor thermal care. However, the phenomenon of poor thermal care practice appears to be different in other low-middle income countries. In Uganda, about $60 \%$ of the mothers practiced delayed newborn bathing (Kayom, Kakuru, \& Kiguli, 2015) and $86.1 \%$ of newborns were bathed after 24 hours in Nepal (Shiva \& Asmi, 2014).

Cultural beliefs and practices are associated with newborn bathing after delivery in sub-Saharan Africa and other low income countries. In typical rural Ghanaian communities, immediate newborn bathing after delivery is widely prevalent because the baby is considered "dirty" due to the presence of vernix caseosa on the baby's body. This probably explains the findings in the current study despite the emphasis on the practice of safe newborn care. Supporting this contention, Sharma, Van Teijlingen, Hundley, Angell, and Simkhada (2016) concluded that immediate newborn bathing is a customary practice to purify the baby in the rural areas of Nepal. Moreover, the main reason for universal early bathing in Nigeria was a belief that the amniotic fluid that protects the foetus in utero could cause body odour as the child grows (Adejuyigbe et al., 2015).

The current study also found that ethnicity, level of education, parity, place of delivery and knowledge on good thermal care had an independent statistically 
significant relationship with delayed newborn bathing. However, level of education, place of delivery, ethnicity and socioeconomic class emerged as the key predictors in the final model of the multiple logistic regression analysis. In terms of education, mothers who received formal education up to the senior high level and above were more likely to practice delayed newborn bathing than mothers who had lower levels of education and no formal education. This finding is not surprising because women who are highly educated are more likely to have a better understanding of the benefits of delayed newborn bathing. As such, women who understand the benefits of delayed newborn bathing are expected to practice same. Consistent with this, Shoaib et al. (2012), reported that educated women were more likely to break away from tradition to use modern means of safeguarding their own health and that of their children. This is congruent with the finding of Kokebie et al. (2015) where educational status was a predictor of essential newborn care practices which includes good thermal care

Furthermore, the findings of the current study suggest that women who delivered at a health facility were more likely to practice delayed newborn bathing than women who delivered at home. This outcome is attributable to the rural nature of the study area where negative cultural beliefs and practices associated with delayed newborn bathing are inherent. Validating this attribution, a qualitative study in Zambia by Shamba et al. (2014) revealed that the main reason for early newborn bathing was the belief that the baby is dirty, particularly if the baby had an obvious vernix as this was believed to be sperm. Consistent with the finding in the current study, Ayiasi, Criel, Orach, Nabiwemba, and Kolsteren (2014) indicated that women who reported health facility delivery were more likely to practice delayed newborn bathing than women who reported home delivery. Likewise, in Tanzania, delayed newborn bathing was almost universal for those who delivered in a facility, but was varied among home deliveries (Adejuyigbe et al., 2015), indicating that facility delivery was a significant predictor of delayed newborn bathing. Contrary to the findings from this study and what has been widely reported in the literature, Kumola (2015) found that place of delivery was not a predictor of good thermal care. Additionally, a cross sectional study by Baqui et al. (2007) in India also revealed that place of delivery did not predict the practice of delayed newborn bathing. Despite facility delivery emerging as a predictor of delayed newborn bathing, the descriptive results showed that facility delivery constituted $84.8 \%$ of early newborn bathing whilst $15.2 \%$ were home deliveries. Nevertheless, in the multivariate analysis, home delivery was not a significant predictor of delayed newborn bathing, possibly due to the small number of home deliveries in the sample population (11.5\%), therefore a lack of statistical power to determine the association. According to Button et al. 
(2013), a study with low statistical power has a reduced chance of detecting a true effect.

\section{Conclusion}

Despite high rate of facility delivery as reported in the study, the practice of delayed bathing until after 24 hours of delivery was very low. The practice of early newborn bathing was still found among mothers who indicated to have delivered in a health facility. As a consequence, the probability of the practice of early newborn bathing within the health facilities is high; since majority of deliveries are usually discharged home after 24 hours of delivery. This implies that health care professionals may not have adequate understanding of the actual number of hours to delay newborn bathing or the policy is poorly implemented. The GHS, Christian Health Association of Ghana (CHAG) and other agencies of newborn health should organise regular in-service training for its staff on newborn care practices, especially newly qualified staff.

\section{Acknowledgement}

My heartfelt thanks go to the respondents who agreed to participate in the study for their understanding and cooperation throughout the study.

\section{References:}

1. Adejuyigbe, E. A., Bee, M. H., Amare, Y., Omotara, B. A., Iganus, R. B., Manzi, F., . . . Hill, Z. E. (2015). "Why not bathe the baby today?": A qualitative study of thermal care beliefs and practices in four African sites. BMC pediatrics, 15(1), 156. doi: http://dx.doi.org/10.1186/s12887-015-0470-0

2. Adewemimo, A. W., Msuya, S. E., Olaniyan, C. T., \& Adegoke, A. A. (2014). Utilisation of skilled birth attendance in Northern Nigeria: a cross-sectional survey. Midwifery, 30(1), e7-e13.

3. Afulani, P. A. (2015). Determinants of maternal health and healthseeking behavior in sub-Saharan Africa: The role of quality of care. Retrieved 20th June, 2017, from http://escholarship.org/uc/item/1pt4h3zh

4. Akter, T., Dawson, A., \& Sibbritt, D. (2015). What impact do essential newborn care practices have on neonatal mortality in low and lowermiddle income countries? Evidence from Bangladesh. Journal of Perinatology, 36(3), 225-230. doi: http://dx.doi.org/10.1038/jp.2015.181

5. Akter, T., Dawson, A., \& Sibbritt, D. (2016). The determinants of essential newborn care for home births in Bangladesh. Public Health, $141,7-16$. 
6. Alemayehu, M., \& Mekonnen, W. (2015). The prevalence of skilled birth attendant utilization and its correlates in North West Ethiopia. BioMed research international, 2015(436938), 8. doi: http://dx.doi.org/10.1155/2015/436938

7. Allison, P. D. (2012). Logistic regression using SAS: Theory and application. The American Statistician, 67(4), 265 - 267.

8. Ameh, C. A., \& van den Broek, N. (2015). Making It Happen: Training health-care providers in emergency obstetric and newborn care. Best Practice \& Research Clinical Obstetrics \& Gynaecology, 29(8), 10771091. doi: http://dx.doi.org/10.1016/j.bpobgyn.2015.03.019

9. Ayiasi, R. M., Criel, B., Orach, C. G., Nabiwemba, E., \& Kolsteren, P. (2014). Primary healthcare worker knowledge related to prenatal and immediate newborn care: a cross sectional study in Masindi, Uganda. BMC health services research, 14(1), 1. doi: http://dx.doi.org/10.1186/1472-6963-14-65

10. Ayiasi, R. M., Kasasa, S., Criel, B., Orach, C. G., \& Kolsteren, P. (2014). Is antenatal care preparing mothers to care for their newborns? A community-based cross-sectional study among lactating women in Masindi, Uganda. BMC pregnancy and childbirth, 14(1), 114. doi: http://dx.doi.org/10.1186/1471-2393-14-114

11. Bang, K., Lee, I., Chae, S., Debeb, H., \& Kang, H. (2015). Women's Perceptions about Pregnancy and Childbirth and Their Perceived Maternal and Newborn Health Problems in Tigray District, Ethiopia. J Preg Child Health, 2(155), 2. doi: http://dx.doi.org/10.4172/2376127X.1000155

12. Baqui, A. H., Williams, E., Darmstadt, G., Kumar, V., Kiran, T., Panwar, D., .. A Ahuja, R. (2007). Newborn care in rural Uttar Pradesh. The Indian Journal of Pediatrics, 74(3), 241-247. doi: http://dx.doi.org/10.1007/s12098-007-0038-6

13. Bawku Municipal Health Directorate. (2014). Annual reports on neonatal mortality rate.

14. Berhe, M., Medhaniye, A. A., Kahsay, G., Birhane, E., \& Abay, M. (2017). Essential neonatal care utilization and associated factors among mothers in public health facilities of Aksum Town, North Ethiopia, 2016. PloS one, 12(4), e0175902. doi: http://dx.doi.org/10.1371/journal.pone.0175902

15. Bhutta, Z. A., Cabral, S., Chan, C.-w., \& Keenan, W. J. (2012). Reducing maternal, newborn, and infant mortality globally: an integrated action agenda. International Journal of Gynecology \& Obstetrics, 119, S13-S17.

16. Bhutta, Z. A., Das, J. K., Bahl, R., Lawn, J. E., Salam, R. A., Paul, V. K., .. Chou, V. B. (2014). Can available interventions end preventable 
deaths in mothers, newborn babies, and stillbirths, and at what cost? The Lancet, 384(9940), 347-370.

17. Button, K. S., Ioannidis, J. P., Mokrysz, C., Nosek, B. A., Flint, J., Robinson, E. S., \& Munafò, M. R. (2013). Power failure: why small sample size undermines the reliability of neuroscience. Nature Reviews. Neuroscience, 14(5), 365-376. doi: http://dx.doi.org/10.1038/nrn3475

18. Callaghan-Koru, J. A., Seifu, A., Tholandi, M., de Graft-Johnson, J., Daniel, E., Rawlins, B., . . . Baqui, A. H. (2013). Newborn care practices at home and in health facilities in 4 regions of Ethiopia. BMC pediatrics, 13(1), 1. doi: http://dx.doi.org/10.1186/1471-2431-13-198

19. Chichiabellu, T. Y., Mekonnen, B., Astawesegn, F. H., Demissie, B. W., \& Anjulo, A. A. (2018). Essential newborn care practices and associated factors among home delivered mothers in Damot pulasa Woreda, southern Ethiopia. Reproductive health, 15(1), 162.

20. Dickson, K. S., Adde, K. S., \& Amu, H. (2016). What Influences Where They Give Birth? Determinants of Place of Delivery among Women in Rural Ghana. International Journal of Reproductive Medicine, 2016(2016), $8 . \quad$ doi: http://dx.doi.org/10.1155/2016/7203980

21. Enuameh, Y. A. K., Okawa, S., Asante, K. P., Kikuchi, K., Mahama, E., Ansah, E., . . . Nanishi, K. (2016). Factors influencing health facility delivery in predominantly rural communities across the three ecological zones in Ghana: A cross-sectional study. PloS one, 11(3), e0152235. doi: http://dx.doi.org/10.1371/journal.pone.0152235

22. Fagbamigbe, A. F., \& Idemudia, E. S. (2015). Barriers to antenatal care use in Nigeria: evidences from non-users and implications for maternal health programming. BMC pregnancy and childbirth, 15(1), 95. doi: http://dx.doi.org/10.1186/s12884-015-0527-y

23. Fagbamigbe, A. F., \& Idemudia, E. S. (2017). Wealth and antenatal care utilization in Nigeria: Policy implications. Health Care for Women International, 38(1), 17-37. doi: http://dx.org.org/10.1186/s12884-015-0527-y

24. Ghana Statistical Service. (2015). Ghana Demographic and Health Survey, 2014 Retrieved 8th August 2016, from http://www.statsghana.gov.gh/docfiles/publications/Ghana\%20DHS \%202014\%20-\%20KIR\%20-\%206\%20April\%202015.pdf

25. Gitonga, E. (2017). Determinants of Focused Antenatal Care Uptake among Women in Tharaka Nithi County, Kenya. Advances in Public Health, 2017(2017), 4. doi: https://doi.org/10.1155/2017/3685401

26. Gul, S., Khalil, R., Yousafzai, M. T., \& Shoukat, F. (2014). Newborn care knowledge and practices among mothers attending pediatric 
outpatient clinic of a hospital in Karachi, Pakistan. International journal of health sciences, 8(2), 167-175.

27. Harrell, F. (2015). Regression modeling strategies: with applications to linear models, logistic and ordinal regression, and survival analysis: Springer.

28. Kabwijamu, L., Waiswa, P., Kawooya, V., Nalwadda, C. K., Okuga, M., \& Nabiwemba, E. L. (2016). Newborn Care Practices among Adolescent Mothers in Hoima District, Western Uganda. PloS one, 11(11), e0166405.

doi: http://dx.doi.org/10.1371/journal.pone.0166405

29. Kawakatsu, Y., Sugishita, T., Oruenjo, K., Wakhule, S., Kibosia, K., Were, E., \& Honda, S. (2014). Determinants of health facility utilization for childbirth in rural western Kenya: cross-sectional study. BMC pregnancy and childbirth, 14(1), 265. doi: http://dx.doi.org/10.1186/1471-2393-14-265

30. Kayom, V. O., Kakuru, A., \& Kiguli, S. (2015). Newborn care practices among mother-infant Dyads in urban Uganda. International journal of pediatrics, $2015 . \quad$ doi: http://dx.doi.org/10.1155/2015/815938

31. Khanal, V., Gavidia, T., Adhikari, M., Mishra, S. R., \& Karkee, R. (2014). Poor thermal care practices among home births in Nepal: further analysis of Nepal Demographic and Health Survey 2011. PloS one, 9(2), e89950. doi: http://dx.doi.org/10.1371/journal.pone.0089950

32. King'oo, B. M. (2015). Factors influencing attendance to antenatal care services in Kenya, the case of Somali women in Eeastleigh Nairobi county, Kenya. University of Nairobi.

33. Kinney, M. V., Cocoman, O., Dickson, K. E., Daelmans, B., Zaka, N., Rhoda, N. R., . . . Darmstadt, G. L. (2015). Implementation of the Every Newborn Action Plan: Progress and lessons learned. Seminars in Perinatology, 39(5), 326-337. doi: http://dx.doi.org/10.1053/j.semperi.2015.06.004

34. Kokebie, T., Aychiluhm, M., \& Alamneh, G. D. (2015). Community Based Essential New Born Care Practices and Associated Factors among Women in the Rural Community of Awabel District, East Gojjam Zone, Amhara, Ethiopia, 2013. International Journal of Advances in Scientific Research, 1(1), 17-27. doi: http://dx.doi.org/10.7439/ijasr

35. Kumola, A. M. (2015). Newborn care practices among postnatal mothers in Garissa County, Kenya. Kenyatta University.

36. Lawn, J. E., Davidge, R., Paul, V. K., von Xylander, S., de Graft Johnson, J., Costello, A., . . Molyneux, L. (2013). Born too soon: care 
for the preterm baby. Journal of Reproductive Health, 10(1), S5. doi: http://dx.doi.org/10.1186/1742-4755-10-S1-S5

37. Lunze, K., Bloom, D. E., Jamison, D. T., \& Hamer, D. H. (2013). The global burden of neonatal hypothermia: systematic review of a major challenge for newborn survival. BMC medicine, 11(1), 24.

38. Marianna, M. (2011). What are the major ethical issues in conducting research? Is there a conflict between the research ethics and the nature of nursing? Health Science Journal, 5(1), 3-14.

39. Muhwava, L. S., Morojele, N., \& London, L. (2016). Psychosocial factors associated with early initiation and frequency of antenatal care (ANC) visits in a rural and urban setting in South Africa: a crosssectional survey. BMC pregnancy and childbirth, 16(1), 18. doi: http://dx.doi.org/10.1186/s12884-016-0807-1

40. Munn-Giddings, C., \& Winter, R. (2013). A handbook for action research in health and social care. 24(2), 153-154. doi: http://dx.doi.org/10.1016/j.nedt.2003.12.003

41. Onalo, R. (2013). Neonatal hypothermia in sub-Saharan Africa: a review. Nigerian journal of clinical practice, 16(2), 129-138. doi: http://dx.doi.org/10.4103/1119-3077.110120

42. Pell, C., Meñaca, A., Were, F., Afrah, N. A., Chatio, S., Manda-Taylor, L., . . Kalilani, L. (2013). Factors affecting antenatal care attendance: results from qualitative studies in Ghana, Kenya and Malawi. PloS one, 8(1), e53747. doi: https://doi.org/10.1371/journal.pone.0053747

43. Rama, R., Gopalakrishnan, S., \& Udayshankar, P. (2014). Assessment of knowledge regarding new-born care among mothers in Kancheepuram district, Tamil Nadu.

44. Renfrew, M. J., McFadden, A., Bastos, M. H., Campbell, J., Channon, A. A., Cheung, N. F., . . . Malata, A. (2014). Midwifery and quality care: findings from a new evidence-informed framework for maternal and newborn care. The Lancet, 384(9948), 1129-1145. doi: http://dx.doi.org/10.1016/S0140-6736(14)60789-3

45. Saaka, M., \& Iddrisu, M. (2014). Patterns and determinants of essential newborn care practices in rural areas of northern Ghana. International Journal of Population Research, 2014. doi: http://dx.doi.org/10.1155/2014/404387

46. Salkind, N. J. (2010). Encyclopedia of research design (Vol. 1): Sage.

47. Semanew, Y., Etaye, M., Tizazu, A., Abebaw, D., \& Gebremedhin, T. (2019). Newborn care practices and its determinants among postnatal mothers in Dessie Referral Hospital, Northeast Ethiopia. BMC research notes, $12(1), 96$.

48. Seyum, T., \& Ebrahim, E. (2015). Proportion of Neonatal Hypothermia and Associated Factors among New-borns at Gondar 
University Teaching and Refferal Hospital, Northwest Ethiopia: A Hospital Based Cross Sectional Study. General Medicine: Open Access, 3(4), 198. doi: http://dx.doi.org/10.4172/2327-5146.1000198

49. Shamba, D., Schellenberg, J., Hildon, Z. J.-L., Mashasi, I., Penfold, S., Tanner, M., . . . Hill, Z. (2014). Thermal care for newborn babies in rural southern Tanzania: a mixed-method study of barriers, facilitators and potential for behaviour change. BMC pregnancy and childbirth, 14(1), 267. doi: http://dx.doi.org/10.1186/1471-2393-14-267

50. Sharma, S., Van Teijlingen, E., Hundley, V., Angell, C., \& Simkhada, P. (2016). Dirty and 40 days in the wilderness: Eliciting childbirth and postnatal cultural practices and beliefs in Nepal. BMC pregnancy and childbirth, 16(1), 147. doi: http://dx.doi.org/10.1186/s12884-0160938-4

51. Shiva, R. A., \& Asmi, P. (2014). Place of delivery and newborn care practices in a village of Kaski district: a cross sectional study from Nepal. Journal of Biomedical Sciences, 1(2), 6-11. doi: http://dx.doi.org/10.3126/jbs.v1i2.11863

52. Shoaib, M., Munir, A., Masood, M., Ali, Q., \& Sher, F. (2012). Education as a Source of Child Health Care Practices: A Case of Mothers in Tehsil Kharian, Gujrat-Pakistan. World Applied Sciences Journal, 19(5), 754-761. doi: http://dx.doi.org/10.5829/idosi.wasj.2012.19.05.2767

53. Sibley, L. M., Tesfaye, S., Fekadu Desta, B., Hailemichael Frew, A., Kebede, A., Mohammed, H., . . . Hepburn, K. (2014). Improving maternal and newborn health care delivery in rural Amhara and Oromiya regions of Ethiopia through the Maternal and Newborn Health in Ethiopia Partnership. Journal of Midwifery \& Women's Health, 59(s1), S6-S20. doi: http://dx.doi.org/10.1111/jmwh.12147

54. Sines, E., Syed, U., Wall, S., \& Worley, H. (2007). Postnatal care: A critical opportunity to save mothers and newborns. Policy Perspectives on Newborn Health, 1-7.

55. Tegene, T., Andargie, G., Nega, A., \& Yimam, K. (2015). Newborn Care Practice and Associated Factors among Mothers who gave Birth within One Year in Mandura District, Northwest Ethiopia. Clinics Mother Child Health, 12(172), 2. doi: http://dx.doi.org/10.4172/20907214.1000172

56. Waiswa, P., Kallander, K., Peterson, S., Tomson, G., \& Pariyo, G. W. (2010). Using the three delays model to understand why newborn babies die in eastern Uganda. Tropical medicine \& international health, 15(8), 964-972. doi: http://dx.doi.org/10.1111/j.13653156.2010.02557.x 
57. World Health Organization. (2009). Global health risks: mortality and burden of disease attributable to selected major risks: World Health Organization.

58. World Health Organization. (2012). Maternal, newborn, child and adolescent health approved by the WHO Guidelines Review Committee. Handbook for guideline development. Geneva: WHO.

59. Yamane, T. (1967). Elementary sampling theory.

\section{Appendix A: Ethical Approval}

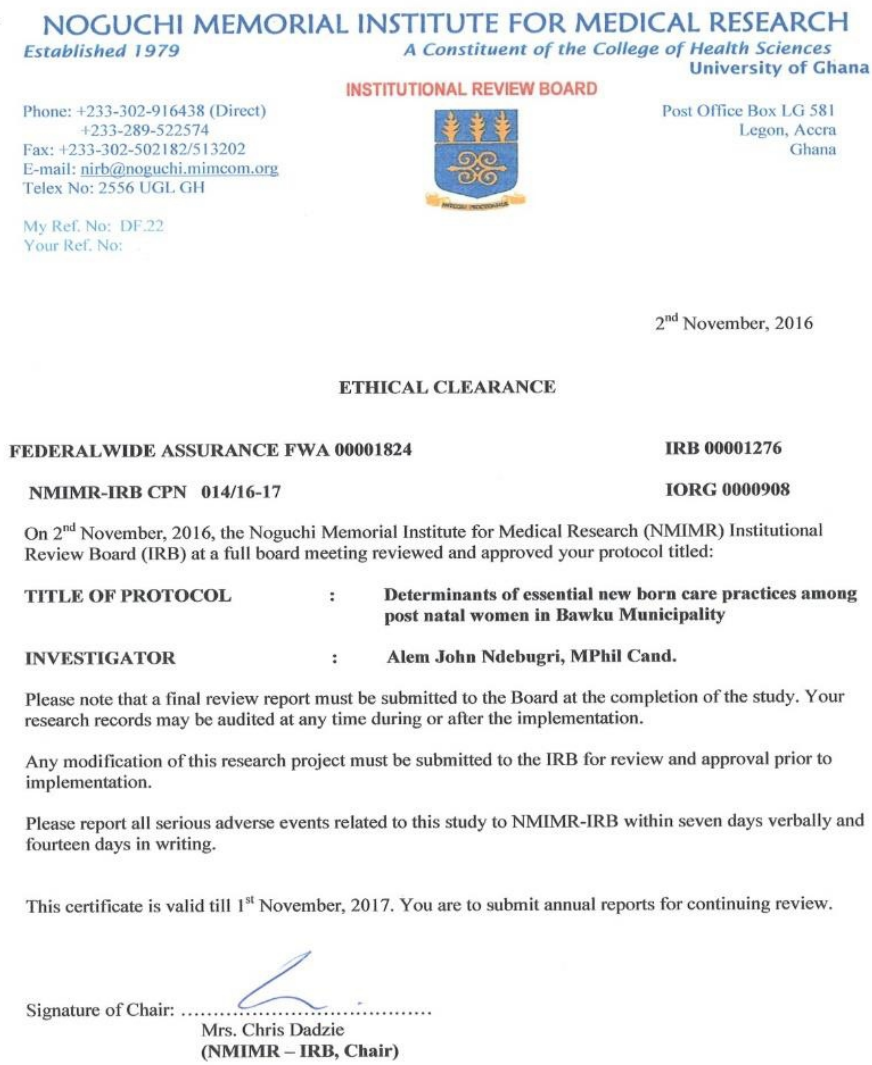

